Fecha de recepción: febrero 2019 Fecha de aceptación: julio 2019 Versión final: noviembre 2020

\section{Praias Accessíveis e Surf Adaptado no Brasil: inovação social baseado no Design Universal}

Denise Siqueira ${ }^{1}$, Lino Fernando Bragança Peres ${ }^{2}$

y Marcos Abilio Bosquetti ${ }^{3}$

Resumo: $\mathrm{O}$ lazer junto a natureza é um direito de todos, no entanto o acesso às praias ainda é um grande desafio para as pessoas com deficiência ou mobilidade reduzida. $\mathrm{O}$ propósito deste artigo é estimular iniciativas voltadas a acessibilidade das praias e a inclusão social das pessoas com deficiência por meio da aplicação dos princípios do desenho universal nos projetos urbanísticos e da prática de esportes adaptados. Este artigo faz uma breve introdução sobre os direitos das pessoas com deficiência, os princípios do desenho universal e o papel da inovação social na construção de uma sociedade inclusiva e discute os resultados de um estudo empírico pioneiro no Brasil realizado por uma pesquisadora insider que testou os programas de acessibilidade das praias Brasileiras e de inclusão social por meio do surf adaptado, considerados casos de sucesso de inovação social. Este artigo também visa despertar o interesse dos pesquisadores na realização de estudos cross-culturais de acessibilidade nos países da América Latina.

Palavras chave: Inovação social - Design Universal - Accessibilidade - Mobilidade reduzida - Surf Adaptado.

[Resumos em espanhol e inglês na página 162]

(1) Possui graduação em Relações Internacionais pela Universidade do Vale do Itajai (UNIVALI). Mestranda na Pós-Graduação em Urbanismo, História e Arquitetura da Cidade - (PGAU-Cidade) pela Universidade Federal de Santa Catarina (UFSC).

(2) Arquiteto pela Faculdade de Arquitetura pela Universidade Federal do Rio Grande do Sul (1977), mestre em Arquitetura (1986) e doutor em Urbanismo (1994) pela Facultad de Arquitectura División de Estudios de Posgrado - Universidad Nacional Autónoma de Mexico. Ingressou na UFSC em 1978 e atualmente é professor associado do Departamento de Arquitetura e Urbanismo da Universidade Federal de Santa Catarina e do Programa de Pós-Graduação - "Urbanismo, História e Arquitetura da Cidade".

(3) Possui graduação em administração de empresas pela Faculdade de Ciências Contábeis e Administrativa de Rolândia (1989); especialização em tecnologia da informação pelo Instituto Superior de Pós-Graduação de Curitiba (1994); mestrado em administração pela University of Bath, Inglaterra (2000); doutorado em administração pela Universidade de São Paulo FEA/USP (2009) modalidade sanduíche no exterior com estágios na McGill University, Montreal, Canadá (2007) e University of Melbourne, Austrália (2008); e pós-doutorado na San Diego State University, California, USA (2016-2017). Professor da Universidade Federal de Santa Catarina - UFSC no Departamento de Ciências de Administração. 


\section{Introdução}

O lazer junto a natureza é um direito social assegurado pela Constituição Federal a todos os cidadãos, contudo o acesso às praias ainda é um grande desafio para as 46 milhões de pessoas com deficiência no Brasil. A existência de barreiras urbanísticas e atitudinais impedem, não apenas o lazer dessas pessoas junto a natureza, mas também a sua inclusão social. Nos últimos 8 anos de incorporação da Convenção da ONU sobre os Direitos das Pessoas com Deficiência, o Brasil tem construído um robusto arcabouço legal e normativo voltado para a garantia da acessibilidade e inclusão social das pessoas com deficiência, no entanto, são raros os casos de sua efetiva aplicação para permitir o lazer e a prática de esportes junto a natureza.

Inconformados com as barreiras urbanísticas e atitudinais que impedem o exercício de seus direitos, algumas pessoas com deficiência assumem o papel de agente de transformação desta realidade. A partir da criatividade solidária, idealizam e implementam inovações sociais que ultrapassam os limites tradicionais que separam os 3 setores da economia e geram impacto coletivo para transformar a sociedade.

Assim, o presente artigo apresenta o surf adaptado como esporte inclusivo e faz uma breve introdução sobre os direitos das pessoas com deficiência, os princípios do desenho universal nos projetos urbanísticos e o papel da inovação social na transformação da sociedade, formando assim o referencial teórico que fundamenta a discussão dos resultados de um estudo empírico pioneiro no Brasil que adota a estratégia de estudo multicasos com abordagem qualitativa para investigar programas de acessibilidade em 15 praias Brasileiras localizadas nos Estados do Rio de Janeiro, São Paulo e Santa Catarina e dois programas de inclusão social por meio do surf adaptado para pessoas com deficiência.

Este artigo é fruto de uma dissertação de mestrado em arquitetura e urbanismo realizado por uma pesquisadora insider que atualmente é usuária de cadeira de rodas e foi a campo testar a acessibilidade das praias e o surf inclusivo (Siqueira, 2017). As considerações finais convidam a uma reflexão sobre a mudança de paradigma, não só no pensamento, mas também nas ações direcionadas à tradução de aspiração à realização da inclusão social das pessoas com deficiência e aponta os passos fundamentais que devem ser dados para mudar o quadro de marginalização dessas pessoas no Brasil.

\section{Surf Adaptado e Inclusivo}

O surf tem crescido rapidamente em popularidade nos cinco continentes e o Brasil ocupa a terceira posição em número de surfistas, depois dos Estados Unidos e da Austrália. Na América Latina destaca-se também o crescimento do esporte no México, Costa Rica, Peru e Chile. A International Surfing Association (ISA), autoridade mundial do surf, com sede na Califórnia, estima em 35 milhões o número de surfistas no mundo (ISA, 2014). O Dia Internacional do Surf é celebrado em 20 de junho reunido diferentes gerações de surfistas e simpatizantes do esporte em apreciação do surf e do meio ambiente. Em Agosto de 2016 o surf foi oficialmente reconhecido como esporte olímpico e estreará em 2020 nas Olimpíadas de Tóquio (IOC, 2017). 
O surf vem atraindo novos praticantes de grupos demográficos mais amplos do que apenas o público jovem masculino (Gia, 2011). O crescimento das escolas de surf e das agências de turismo especializadas, os eventos destinados a atrair novos surfistas, as mídias e redes sociais dedicadas aos esportes na natureza, e a busca por um estilo de vida saudável estão contribuindo para o crescimento mundial do esporte (Reynolds e Hritz, 2012).

Em 2015 a ISA, lançou o Campeonato Mundial de Surf Adaptado e em estilo paraolímpico, uma iniciativa que visa promover a inclusão das pessoas com deficiência ou mobilidade reduzida no mundo do surf para que todos possam praticar o esporte. No campeonato de 2017 participaram 109 atletas representando 26 países, sendo 7 da América Latina: Argentina, Brasil, Chile, Colômbia, Costa Rica, México e Peru, com destaque para a equipe brasileira que conquistou, pelo segundo ano consecutivo, a medalha de ouro (ISA, 2017). Vários estudos comprovam os efeitos benéficos da prática de esportes no mar para a nossa saúde física e emocional. Em seu livro Blue Mind o Dr. Wallace Nichols explica por que as pessoas se encontram em um estado meditativo e descontraído quando estão no mar. A flutuação na água salgada aumenta a liberação de dopamina e serotonina e tem o poder de abrandar as ondas cerebrais, ajudando a proporcionar um estado contemplativo da natureza e de atenção plena no momento presente, contribuindo para a redução dos sintomas de ansiedade e depressão. Segundo o autor, atividades físicas na água fria do mar também ativam os receptores de temperatura da epiderme que liberam hormônios como endorfinas, adrenalina e cortisol, proporcionando benefícios terapêuticos para problemas musculoesqueléticos (Nichols, 2014).

As pessoas com deficiência estão buscando cada vez mais os benefícios terapêuticos proporcionados pelas atividades físicas no mar, porém dependem do acesso as praias e suporte para a prática de esportes aquáticos como o surf adaptado.

\section{As Pessoas com Deficiência e Seus Direitos}

Os direitos das pessoas com deficiência têm sido tema da agenda da Organização das Nações Unidas. Em 1992 a ONU instituiu o Dia Internacional das Pessoas com Deficiência, comemorado no dia 3 de Dezembro, com o objetivo de promover uma maior compreensão dos assuntos concernentes à deficiência e para mobilizar a defesa da dignidade, dos direitos e o bem estar das pessoas com deficiência. Em 2006 a Assembleia Geral das Nações Unidas adotou a Convenção da ONU sobre os Direitos das Pessoas com Deficiência (CRPD), um tratado internacional que visa assegurar o exercício pleno e equitativo de todos os direitos humanos para as pessoas com deficiência e promover a sua inclusão social. A ratificação da Convenção compromete o país em direito internacional a uma série de princípios gerais fundamentais, como o direito à vida, educação, saúde, emprego, cultura, lazer e esporte (United Nations, 2006).

Nos 10 anos desde sua adoção, a CRPD foi uma das mais rapidamente ratificadas de todos os tratados de direitos humanos internacionais, contando com 160 países signatários e se tornou um catalisador no movimento global para considerar as pessoas com deficiência como membros da sociedade e não como objetos de caridade, tratamento médico e proteção social. $\mathrm{O}$ tratamento de pena ou de inferioridade reservado às pessoas com deficiência 
advindos da noção de que essas pessoas são inferiores às pessoas sem deficiência caracteriza-se como uma opressão passiva denominada de capacitismo (Pereira, 2008). Esta noção equivocada sobre as pessoas com deficiência também é a principal causa da discriminação e do preconceito presentes em nossa sociedade.

A CRPD considera a pessoa com deficiência como aquela que tem impedimento de longo prazo de natureza física, mental, intelectual ou sensorial, o qual, em interação com uma ou mais barreiras, pode obstruir sua participação plena e efetiva na sociedade em igualdade de condições com as demais pessoas (United Nations, 2006). Esta nova abordagem social surgiu como alternativa ao modelo médico da deficiência, que reconhece na lesão, na doença ou na limitação física a causa primeira da desigualdade social e das desvantagens vivenciadas pelas pessoas com deficiência, ignorando o papel da sociedade na sua opressão e marginalização. O modelo social amplia o conceito de deficiência ao considerar como um fator limitador as barreiras existentes no meio em que a pessoa com deficiência está inserida e não apenas as suas limitações funcionais, reconhecidas como atributos da pessoa e inerentes à diversidade humana.

Para a ONU, a CRPD oferece uma oportunidade única para melhorar a qualidade de vida de aproximadamente um bilhão de pessoas vivendo com algum tipo de deficiência, ou seja, uma em cada sete pessoas no mundo (United Nations, 2016). Estudos da Organização Mundial da Saúde apontam que $80 \%$ das pessoas com deficiência vivem em países em desenvolvimento (WHO, 2011). A ONU também reconhece que ainda restam enormes desafios no acesso total aos direitos por parte das pessoas com deficiência e destaca que a Agenda 2030 para o Desenvolvimento Sustentável estabelece uma fase nova e encorajadora na área da deficiência e desenvolvimento. A nova agenda global contém 7 objetivos que se referem explicitamente a pessoas com deficiência e suas necessidades (United Nations, 2017).

O Brasil incorporou a CRPD em 2009 com equivalência de ementa constitucional e criou a Secretaria Nacional de Promoção dos Direitos da Pessoa com Deficiência (SNPD) para atuar na articulação e coordenação das políticas públicas voltadas para as 46 milhões de pessoas com deficiência no Brasil (SNPD, 2012).

Em Junho de 2017 o Brasil assinou um termo de cooperação Latino-Americana com o Chile, Colômbia e México para promover o desenvolvimento conjunto de programas, capacitação e cooperação em pesquisa e conhecimentos científicos voltadas as pessoas com deficiência (SNPD, 2017).

\section{Desenho Universal, Acessibilidade e Inclusão Social}

O processo de inclusão social pressupõe a construção de uma sociedade inclusiva e acessível a todos os cidadãos, não permitindo que uma parcela da população seja alijada de seus direitos. Para isto, é necessário que os locais públicos tornem-se acessíveis também às pessoas com deficiência, eliminando as barreiras para que este direito possa ser exercido (Sassaki, 2010).

A acessibilidade e a inclusão social das pessoas com deficiência no Brasil tem amparo legal por meio da Lei da Acessibilidade (Lei 10.098, 2000 regulamentada pelo Decreto Federal 5.296, 2004) e da Lei Brasileira de Inclusão da Pessoa com Deficiência (Lei 13.146, 2015). A 
Lei define acessibilidade como a possibilidade e condição de alcance para utilização, com segurança e autonomia, dos espaços, mobiliários e equipamentos urbanos, das edificações, dos transportes e dos sistemas e meios de comunicação, por pessoas com deficiência ou com mobilidade reduzida, enquanto que a barreira é definida como qualquer entrave ou obstáculo que limite ou impeça o acesso, a liberdade de movimento e a circulação com segurança das pessoa com deficiência, sendo classificadas em barreiras urbanísticas existentes nas vias e nos espaços públicos de uso coletivo, barreiras nas edificações de uso público e coletivo, barreiras nos sistemas e meios de transportes coletivos, e barreiras nas comunicações (Lei 10.098, 2000).

Tanto a Lei de Acessibilidade como a Lei Brasileira de Inclusão da Pessoa com Deficiência determinam que a concepção dos projetos urbanísticos devem atender aos princípios do Desenho Universal que consiste na criação de ambientes que possam ser usados por todas as pessoas, sem necessidade de adaptação ou projeto específico (Lei 10.098, 2000; Lei 13.146, 2015). As Leis brasileiras estão alinhadas com a CRPD que também recomenda a adoção dos princípios do desenho universal e salienta que a sua aplicação não excluirá as ajudas técnicas para pessoas com deficiência, quando necessárias (United Nations, 2006). A expressão Universal Design (Desenho Universal) foi usada pela primeira vez nos Estados Unidos, em 1985, pelo arquiteto Ron Mace, fundador do Center for Universal Design (Centro de Desenho Universal) na Universidade Estadual da Carolina do Norte, que influenciou a mudança de paradigma no desenvolvimento de projetos urbanos, de arquitetura e design. Para Mace, Hardie \& Place (1991), o desenho universal aplicado a um projeto consiste na criação de ambientes que possam ser usados por todas as pessoas, na sua máxima extensão possível.

O Center for Universal Design estabeleceu sete princípios do desenho universal que passaram a ser mundialmente adotados em planejamentos e obras de acessibilidade. Estes princípios priorizam: 1) desenho equitativo para ser utilizado por pessoas com habilidades diversas, evitando a segregação; 2) flexibilidade de uso; 3) uso simples e intuitivo; 4) informação de fácil percepção, 5) tolerância a erros dos usuários para preservar a segurança; 6) esforço físico mínimo; e 7) dimensionamento de espaços para acesso e uso abrangente (Center for Universal Design, 1997).

\section{Inovação Social}

O termo Inovação Social surgiu na década de 1970 com uma definição bastante ampla que considerava inovação social como uma nova forma de fazer as coisas para atender às necessidades sociais (Taylor, 1970). O termo foi disseminado nos anos 1980 pelo pesquisador da área de administração Peter Drucker e pelo empreendedor social Michael Young, fundador da Open University (Drucker, 1987; Young, 1983), mas passou a ser amplamente utilizado a partir da virada do milênio.

A Stanford Social Innovation Review, respeitada publicação científica sobre o tema, adota o seguinte conceito de Inovação Social definido pelos professores e diretores do Center for Social Innovation da Stanford Graduate School of Business na Califórnia: "Inovação Social é uma nova solução para um problema social; uma solução mais efetiva, eficiente, susten- 
tável ou justa do que as soluções já existentes e cujo valor gerado beneficia, prioritariamente, a sociedade como um todo e não apenas alguns indivíduos" (Phills Jr., Deiglmeier \& Miller, 2008, p. 36). Os autores destacam que a maioria das soluções sociais inovadoras ultrapassam os limites tradicionais que separam organizações governamentais, empresariais e não governamentais sem fins lucrativos (ONGs).

O potencial existente nas parcerias entre os três setores - publico, privado e sociedade civil representada pelas ONGs- para alavancar a inovação social tem sido cada vez mais estudado, discutido e estimulado (Mintzber, 2015; Hawken, 2007) por ser uma forma de complementação das competências e recursos exigidos para gerar "impacto coletivo" (Kania \& Kramer, 2011, p. 1) e realizar transformações sociais.

Esta breve apresentação do mundo do surf, dos direitos das pessoas com deficiência, dos princípios do desenho universal e da definição de inovação social formam o referencial teórico que orienta a pesquisa de campo e fundamenta a discussão dos resultados deste estudo sobre acessibilidade das praias e surf adaptado no Brasil.

\section{Investigando as Praias Acessíveis do Brasil}

Este artigo é fruto da dissertação de mestrado em arquitetura e urbanismo realizada por uma pesquisadora que atualmente é usuária de cadeira de rodas devido a um acidente automobilístico sofrido aos 21 anos de idade. Trata-se de um estudo empírico pioneiro no Brasil que adota a estratégia de multicasos com abordagem qualitativa para investigar a acessibilidade de 15 praias Brasileiras consideradas acessíveis, localizadas nos Estados do Rio de Janeiro, São Paulo e Santa Catarina e dois programas de inclusão social por meio do surf adaptado para pessoas com deficiência, caracterizando assim uma pesquisa insider, uma vez que a pesquisadora também pertence ao grupo investigado (Adler \& Adler, 1994; Kanuha, 2000). O estudo também pode ser caracterizado como pesquisa-ação, uma vez que a participação da pesquisadora tem o propósito de contribuir para a transformação da realidade estudada (Thiollent, 1992).

Além da observação participante como usuária de cadeira de rodas testando o acesso às praias e como praticante do surf adaptado, a pesquisadora também conduziu 26 entrevistas semiestruturadas com pessoas com deficiência, gestores públicos e idealizadores dos programas de inclusão social.

Os casos foram analisados individualmente utilizando-se da técnica de triangulação de múltiplas fontes de evidências coletadas por diferentes métodos, bem como a criação de uma base de dados dos estudos de casos. Numa segunda etapa foi realizada a análise cruzada de dados, recomendada por Eisenhardt (1989) para identificar, de forma ampliada, padrões de manifestação do fenômeno entre os casos estudados. Vale destacar que este artigo apresenta apenas dois dos 15 casos estudados de praias acessíveis na dissertação de mestrado, mas considera a análise cruzada de todos os dados na discussão dos resultados. Os princípios do desenho universal nortearam a coleta e análise dos dados, com ênfase no princípio de uso equitativo para a concepção de espaços, objetos e produtos que possam ser utilizados por pessoas com capacidades diferentes, evitando assim a segregação. As categorias de análise também foram definidas a partir do ciclo de acessibilidade, uma vez 
que a concepção e implantação de iniciativas voltadas ao acesso das praias por usuários de cadeiras de rodas deve considerar todo o ciclo básico de acessibilidade composto por 5 etapas: 1) acessar o balneário por meio de transporte público ou poder estacionar em vagas reservadas para pessoas com deficiência; 2) acessar a orla da praia (faixa de areia) por meio de esteiras de acesso; 3) ficar na orla da praia com acesso as atividades de lazer e banheiros acessíveis; 4) acessar a água do mar por meio de cadeira anfíbia; e 5) ficar na água para um banho de mar e/ou praticar esportes como surf adaptado em pranchas com design apropriado.

O banheiro acessível, a esteira de acesso e a cadeira anfíbia são elementos fundamentais do ciclo de acessibilidade das praias. Um banheiro acessível, segundo a Norma Brasileira NBR9050 da Associação Brasileira de Normas Técnicas ABNT que determina a acessibilidade a edificações, mobiliário, espaços e equipamentos urbanos (ABNT, 2015), deve ter o piso nivelado, a porta com no mínimo $80 \mathrm{~cm}$ e abertura para fora, uma dimensão mínima de $1,50 \mathrm{~m}$ por $1,70 \mathrm{~m}$ para manobras com cadeira de rodas, barras de apoio, maçanetas de alavanca e torneiras ao alcance do usuário. A esteira de acesso e mobilidade na faixa de areia das praias deve ser firme, estável, antiderrapante, fácil de instalar e altamente resistente, e segundo estudos Norte Americanos a esteira francesa Mobi-Mat, é considerada a melhor solução do mercado, sendo a mais utilizada no mundo (National Center on Accessibility, 2017). Uma cadeira de rodas anfíbia, segundo a instituição Norte Americana Mobility Advisor, deve ter estrutura leve e impermeável e um sistema de rodas grandes e largas que circulam sobre a areia da praia sem afundar e que faça a cadeira flutuar no mar, permitindo ao cadeirante um banho de mar com conforto e segurança. Existem cadeiras anfíbias com 2, 3 ou 4 rodas e modelos motorizados que proporcionam mais autonomia ao usuário (Mobility Advisor, 2017).

\section{Apresentação dos Casos}

\section{Caso \#1 Cidade do Rio de Janeiro: Programas Praia Para Todos e AdaptSurf}

O estudo de caso da cidade do Rio de Janeiro apresenta inicialmente o Programa AdaptSurf por ser pioneiro no Brasil e ter também contribuído para a concepção do Programa Praia Para Todos.

\section{Rio de Janeiro: Programa AdaptSurf}

A Associação Adaptação e Surf - AdaptSurf é uma organização não governamental e sem fins lucrativos idealizada pelo surfista profissional Henrique Saraiva em conjunto com o casal Luiz Phelipe Nobre, fisioterapeuta e Luana Nobre, professora de educação física. A experiência de Henrique Saraiva, que em 1997 sofreu uma lesão medular ocasionada por um tiro durante um assalto e depois de várias cirurgias e fisioterapia voltou a surfar em uma prancha adaptada, inspirou a criação da primeira iniciativa de surf adaptado no Brasil. Para conceber a AdaptSurf seus fundadores pesquisaram nos Estados Unidos, Austrália, Espanha e Portugal as iniciativas bem sucedidas de acessibilidade das praias e surf adaptado. 
A AdaptSurf foi fundada em 2007 com a missão de promover a inclusão e interação social das pessoas com deficiência garantindo igualdade de oportunidades e acesso ao lazer, esporte e cultura do surf por meio da prática do surf adaptado. Para cumprir sua missão, a AdaptSurf mobilizou órgãos públicos para criar toda a estrutura necessária de acesso e permanência das pessoas com deficiência na praia, como a criação de vagas reservadas de estacionamento, construção de rampas de acesso às calçadas de pedestres e banheiros acessíveis. A AdaptSurf também foi pioneira na utilização das esteiras Mobi-Mat e das cadeiras anfíbias no litoral brasileiro. Com o sucesso de sua iniciativa pioneira a AdaptSurf passou a ser convidada para dar consultoria em acessibilidade de praias e surf adaptado em outros Estados do Brasil.

Os fundadores da AdaptSurf acreditam que o surf pode ser uma excelente ferramenta para as questões sociais, culturais e ambientais por se tratar de um esporte saudável, democrático e de interação com a natureza. A partir desta premissa, a ONG organizou em 2009 o Circuito AdaptSurf - primeiro campeonato de surf para pessoas com deficiência do Brasil. Neste evento que acontece anualmente todos os surfistas adaptados tem a oportunidade de demonstrar suas habilidades de surf para o público da praia de Copacabana, uma das mais frequentadas do Rio de Janeiro. Além da competição de surf a AdaptSurf organiza um mutirão de limpeza da orla e oficina de educação ambiental e de yoga, envolvendo todo o público da praia. O evento é encerrado com premiação para todos os competidores. Em 2010 a AdaptSurf lançou o Guia Acessibilidade das Praias contendo informações sobre as condições de acessibilidade e qualidade das ondas das principais praias do litoral do Estado do Rio de Janeiro. O guia é distribuído gratuitamente nas praias da cidade e também pode ser acessado pelos canais da rede social AdaptSurf. Trata-se do primeiro guia publicado no Brasil sobre acessibilidade das praias para as pessoas com deficiência e sobre a classificação das ondas para a prática do surf adaptado (AdaptSurf, 2017).

Em 2011 a AdaptSurf foi convidada para compor o Grupo de Estudos sobre Praia da Associação Brasileira de Normas Técnicas - ABNT que está trabalhando na elaboração de uma norma internacional para a certificação de qualidade ambiental, estrutural e de serviços das praias (Folha de São Paulo, 2011). Segundo os fundadores da AdaptSurf, o estudo está na fase final de aprovação da norma internacional que será adotada por mais de 50 países. Em 2017 o Programa AdaptSurf completou 10 anos de atuação ininterrupta. Os alunos do programa tem acesso a vagas reservadas no estacionamento, esteiras de acesso a faixa de areia, tendas e mesas acessíveis, cadeiras anfíbias, diversos tipos de flutuadores, roupas de lycra e de borracha, diversos modelos e tamanhos de pranchas adaptadas e contam com uma equipe especializada composta por fisioterapeutas, professores de educação física, instrutores de surf adaptado e também uma grupo de estudantes universitários que atuam como voluntários. O programa oferece toda tecnologia assistida necessária para a pratica do surf adaptado e funciona durante o ano todo nos finais de semana das $9 \mathrm{~h}$ as $14 \mathrm{~h}$. Aos sábados na Praia da Barra da Tijuca e aos domingos na Praia do Leblon. No verão 2017 o Programa AdaptSurf atendeu uma média de 60 pessoas com deficiência por dia de funcionamento.

\section{Rio de Janeiro: Programa Praia Para Todos}

Em 2008, logo após o sucesso do programa AdaptSurf, o Instituto Novo Ser e a AdaptSurf uniram suas forças para conceber e lançar um projeto piloto de ampliação das praias 
acessíveis no Rio de Janeiro que foi inicialmente chamado de Projeto Praia Acessível - Lazer Para Todos. O foco deste projeto piloto era proporcionar os recursos necessários para a inclusão social das pessoas com deficiência por meio do lazer e da prática de atividades físicas e desportivas na praia, como o yoga adaptado, hidroginástica em piscina inflável, vôlei sentado de praia, futebol adaptado, frescobol, peteca, handbike e banho de mar assistido -atividade mais procurada pelos participantes.

O Instituto Novo Ser também é uma instituição sem fins lucrativos com a missão de promover os direitos ao lazer das pessoas com deficiência, a equalização das oportunidades e a superação dos obstáculos predominantes no processo de inclusão social. O Instituto foi fundado em 2002 por Maria do Carmo Gonzalez, uma mãe com anseios para reinserir no convício social o seu filho Ricardo Gonzalez que sofreu uma lesão medular e por Sheyla Mattos, fisioterapeuta que acompanhava os desafios da inclusão social enfrentados pela família Gonzales. A iniciativa de levar acessibilidade para todas as praias do Rio de Janeiro foi vislumbrada pelo jovem Ricardo Gonzalez, que procurou a AdaptSurf para juntos criarem o projeto piloto.

O Projeto Piloto Praia Acessível - Lazer Para Todos foi realizado de forma itinerante e funcionando nos finais de semana durante o verão de 2017 nas praias da Barra da Tijuca, Copacabana, Leblon e Ipanema. O projeto piloto despertou a atenção da sociedade e também da Prefeitura Municipal do Rio de Janeiro que passou a apoiar a iniciativa.

Após o sucesso do Projeto Piloto, a iniciativa foi batizada como Programa Praia Para Todos e foi implementado de forma fixa no Posto 5 de Salva-Vidas na Praia de Copacabana e no Posto 3 de Salva-Vidas na Praia da Barra da Tijuca, com funcionamento nos finais de semana durante os 4 meses da temporada de verão. O Programa Praia Para Todos passou a ser coordenado apenas pelo Instituto Novo Ser com foco em atividades físicas, esportes de praia e banho de mar assistido. A ONG AdaptSurf continuou desenvolvendo seu Programa AdaptSurf com foco na prática do surf adaptado e atuando de forma fixa e permanente, durante todo o ano no Posto 11 de Salva-Vidas da Praia do Leblon e no Posto 2 de Salva-Vidas da Praia da Barra da Tijuca. Os dois programas operam bem próximos aos postos de salva-vidas para proporcionar as pessoas com deficiência o monitoramento realizado pelas equipes de bombeiros.

Assim como o Programa AdaptSurf, o Programa Praia Para Todos também precisou providenciar todas as adequações para tornar as praias acessíveis como vagas reservadas nos estacionamentos, esteiras de acesso a faixa de areia, tendas e mesas acessíveis, cadeiras anfíbias, flutuadores e roupas de lycra e de borracha. O Programa Praia Para Todos também disponibiliza os equipamentos esportivos para a prática das atividades de lazer e os serviços de uma equipe especializada composta por fisioterapeutas e professores de educação física que organizam e coordenam as atividades de integração e contam também com o apoio de um grupo de estudantes universitários que atuam como voluntários. Em 2010 o Programa Praia Para Todos passou a contar com o patrocínio da empresa Michelin, filial brasileira da multinacional francesa fabricante de pneus.

O Programa Praia Para Todos também vai comemorar 10 anos de operação e já beneficiou diretamente mais de 6 mil pessoas com deficiência (Acesse, 2017). O idealizador e coordenador do programa, Ricardo Gonzalez, destaca que são necessárias aproximadamente 50 pessoas por dia para a realização das atividades do programa e afirma que o programa 
Praia Para Todos tem contribuído de forma significativa para a melhoria da qualidade de vida e autoestima dos participantes. Ricardo cita como exemplo o caso de Edson Nascimento, atualmente atleta e maratonista da modalidade handbike, uma vez que ele não era praticante de esporte e não frequentava a praia durante muito tempo, até conhecer e participar do Programa Praia Para Todos.

Com relação a questão de transporte público para acesso ao balneário, as pessoas com deficiência contam com o sistema de metrô totalmente acessível e com a 100\% dos ônibus da frota do sistema de transporte rápido BRT Rio também acessíveis.

\section{Caso \#2 Cidade de Santos: Programas Praia Acessível e Surf Inclusivo}

Santos é uma cidade portuária localizada na Ilha de São Vicente no litoral do Estado de São Paulo, a $68 \mathrm{~km}$ da capital. O principal cartão-postal de Santos é a sua orla de $7 \mathrm{kms}$ que abriga o Jardim da Orla de Santos, o Parque do Emissário e a Praça do Surfista.

Com 5.335 metros de comprimento, largura entre 45 e 50 metros e $218.800 \mathrm{~m}^{2}$ de área que abriga 920 canteiros de plantas e mais 1.700 árvores e palmeiras, o Jardim da Orla de Santos entrou para o livro de recordes Guinness Book como o maior jardim de praia do mundo (Guinness, 2005). No Jardim também está situada a Praça do Surfista, uma homenagem ao santista Osmar Gonçalves que em 1938, com apenas 16 anos de idade, entrou para a história do surf por ser o primeiro brasileiro a pegar onda.

Em 2010 o Jardim foi tombado como Patrimônio Histórico da Cidade de Santos e em 2011 foi adaptado para se tornar acessível para as pessoas com deficiência. As vias de passeio da orla foram padronizadas de acordo com o Projeto Calçadas Para Todos, uma iniciativa da Prefeitura Municipal de Santos visando a acessibilidade e segurança de todos os pedestres. Todos os banheiros distribuídos ao longo da orla foram adaptados para se tornarem $100 \%$ acessíveis. Também foram instalados ao longo da orla bebedouros e duchas de água doce para os banhistas (Prefeitura Municipal de Santos, 2017a).

O Parque Municipal Roberto Mario Santini, conhecido como Parque do Emissário é uma extensão do Jardim da Orla de Santos e foi construído sobre a plataforma do emissário submarino que avança 400m mar adentro. Com $42.750 \mathrm{~m} 2$ o Parque do Emissário oferece estrutura esportiva para todas as idades, como pista de cooper, ciclovia, playground, pista de skate projetada para competições internacionais, equipamentos de ginástica ao ar livre, gibiteca, espaço para exposição de artes ao ar livre, sanitários acessíveis e pisos táteis, bicicletário, mesas de jogos ao ar livre, além de áreas verdes e um heliponto (Prefeitura Municipal de Santos, 2017b).

A área também abriga o Museu do Surf e um espaço projetado para competições de surf, com torre de jurados e arquibancada acessível com capacidade para 600 pessoas, junto ao quebra-mar. O Parque do Emissário foi inaugurado em 2009, ampliado em 2013 e depois foi totalmente reurbanizado em 2015 atendendo plenamente a norma técnica ABNT NBR 9050 de Acessibilidade a edificações, mobiliário, espaços e equipamentos urbanos. 


\section{Cidade de Santos: Programa Praia Acessível}

Todas as ações voltadas para a acessibilidade da orla de Santos que antecederam a implantação do Programa Praia Acessível foram fundamentais para o seu sucesso, embora não tenham sido concebidas de forma sistêmica ou visando atender o programa, que foi concebido somente em 2010 pela Secretaria de Estado dos Direitos da Pessoa com Deficiência de São Paulo (SEDPcD-SP) e foi implantado em 2011 na orla de Santos por meio do convênio firmado entre a SEDPcD-SP e a Prefeitura Municipal de Santos.

O Programa Praia Acessível é ofertado pela SEDPcD-SP a todas as prefeituras municipais interessadas, sendo que a Secretaria do Estado fornece as cadeiras anfíbias, flutuadores e esteiras Mobi-Mat com o patrocínio da SABESP - Companhia de Água e Saneamento de São Paulo. Em contrapartida, o município interessado no Programa Praia Acessível deve providenciar banheiros acessíveis, vagas reservadas nos estacionamentos, rampas de acesso a calçadas, monitoramento de um posto salva-vidas e também fornecer uma equipe de pelo menos 3 profissionais da área da saúde, preferencialmente fisioterapeutas e educadores físicos para conduzir as atividades de banho de mar assistido durante a permanência do programa na cidade, uma vez que o programa é itinerante e funciona nos finais de semana e feriados durante aproximadamente um mês da estação de verão em cada cidade conveniada, conforme agenda organizada pela Secretaria de Estado (SEDPcD-SP, 2015).

No caso do Programa Praia Acessível de Santos, a Prefeitura Municipal, além da equipe de profissionais da saúde exigida pelo convênio com a SEDPcD-SP para a prática do banho de mar assistido, fornece também todos os equipamentos e acessórios necessários para a prática de atividades físicas e esportivas na praia, como yoga adaptado, hidroginástica em piscina inflável, vôlei sentado de praia, frescobol e peteca que são organizadas por equipe de educadores físicos também contratados pela Prefeitura Municipal.

Devido ao sucesso e alta taxa de utilização do Programa Praia Acessível na cidade de Santos, a Prefeitura Municipal decidiu adquirir as cadeiras anfíbias e contratar uma equipe permanente de apoio para garantir que as pessoas com deficiência possam desfrutar do programa o ano todo, e não apenas no verão. Com relação a acessibilidade da praia, o Jardim da Orla de Santos já estava totalmente acessível devido às iniciativas e ações que antecederam o programa da Secretaria de Estado.

O Programa Praia Acessível de Santos funciona ao lado do Posto 2 de Salva-Vidas durante o ano todo nos finais de semana e feriados (Universo Online, 2014). Além destas atividades, as pessoas com deficiência contam com aulas de surf adaptado, por meio do Programa Surf Inclusivo.

\section{Cidade de Santos: Programa Surf Inclusivo}

O Programa Surf Inclusivo funciona próximo ao Programa Praia Acessível, no Posto 2 de Salva-Vidas na Escola Pública de Surf em frente a Praça do Surfista no Jardim da Orla de Santos.

A Escola Radical de Surf é a primeira escola pública de surf no Brasil. A escola foi idealizada em 1991 pelo surfista e educador físico Cisco Araña e tem sido mantida desde o início pela Secretaria Municipal de Esportes em parceria com o Rotary Club Santos Praia. Em 2017 a Escola Radical completou 26 anos de atuação voltadas para o surf inclusivo atendendo mais de 30 mil alunos entre 5 e 83 anos de idade. 
Em Novembro de 2014 a Secretaria Municipal de Esportes de Santos lançou o Núcleo de Terapia com Pranchas de Surf Adaptadas para Pessoas com Deficiência e apresentou uma inovação no mundo do surf -a prancha multifuncional que visa garantir mais segurança na prática do surf adaptado. O fundador e coordenador da Escola, Cisco Araña, desenvolveu o equipamento baseado na sua larga experiência como instrutor de alunos com diferentes deficiências. A inovação da prancha multifuncional está na sua simplicidade e adaptabilidade ao tipo de deficiência do surfista a partir de vários módulos removíveis, construídos de material flexível e ante impacto, que permitem anatomicamente um encaixe mais seguro do aluno na prancha. $O$ projeto de design e construção das pranchas multifuncionais foi totalmente patrocinado pelo Rotary Club Santos Praia (Globo Esporte, 2014).

Com a inovação da prancha funcional o Núcleo de Terapia com Pranchas de Surf Adaptadas para Pessoas com Deficiência, composto por uma equipe multidisciplinar nas áreas de educação física, fisioterapia e psicologia, passou a atender pessoas com tipos de deficiências que antes não podiam ser atendidas, tornando o surf mais inclusivo. Em Dezembro de 2017 a Escola Radical de Surf contava com 294 alunos, sendo 88 deles pessoas com deficiência utilizando as pranchas multifuncionais.

Com relação ao transporte coletivo para acessar o Jardim da Orla de Santos, as pessoas com deficiência contam com toda as frotas de ônibus convencional e executivo $100 \%$ acessíveis.

\section{Considerações Finais}

Os 4 programas aqui apresentados que compõem os 2 estudos de caso: Rio de Janeiro e de Santos, podem ser considerados, de acordo com a definição do Center for Social Innovation, como casos de inovação social, uma vez que apresentaram uma nova solução mais eficiente e mais justa para um problema social e cujo valor gerado beneficia, prioritariamente, a sociedade como um todo e não apenas alguns indivíduos ou empresas.

A mídia nacional tem apresentado os dois programas de inclusão pelo surf adaptado como casos de sucesso de inovação social (Folha de São Paulo, 2011). Os programas tem sido procurado por instituições de outros estados do Brasil e até por outros países, como o Chile, México e Uruguai que conheceram o Surf Inclusivo de Santos e passaram a utilizar a prancha multifuncional desenvolvida pelo coordenador do programa.

É importante observar que os 4 programas foram viabilizados por meio de diferentes arranjos envolvendo governo, empresas e ONGs. Os programas exploram o potencial existente nas parcerias entre os 3 setores da economia para a complementação de competências e recursos visando gerar o impacto coletivo (Kania \& Kramer, 2011) necessário para realizar transformações sociais.

Os dois programas de surf adaptado: AdaptSurf no Rio e Surf Inclusivo em Santos operam de forma permanente o ano todo e portanto podem ser considerados como inovações sociais que proporcionam uma solução definitiva.

A participação da pesquisadora insider nas atividades do AdaptSurf e do Surf Inclusivo revelou o grande potencial do esporte como ferramenta de inclusão social. O coordenador do Programa AdaptSurf, Luiz Phelipe Nobre, salienta que: "O objetivo não é ter um can- 
tinho reservado para deficientes, mas sim garantir que a praia seja um ambiente de todos, estimulando a interação e o convívio entre pessoas com e sem deficiência”.

Além do programa de inclusão social por meio do surf adaptado, a ONG AdaptSurf e a Escola Radical também fazem o treinamento de atletas adaptados de alto rendimento e já lançaram atletas brasileiros que conquistaram pela segunda vez consecutiva a medalha de ouro na categoria Equipe no Campeonato Mundial do Surf Adaptado, organizado pela International Surfing Association. Na categoria individual o Brasil é representado pelo aluno da AdaptSurf Davi Teixeira, de apenas 11 anos de idade, que conquistou a medalha de ouro, em 2016, e a de prata em 2017 (ISA, 2017).

Os resultados da investigação, in loco, apontam que os dois programas de acessibilidade: o Praia Para Todos do Rio e o Praia Acessível de Santos consideraram os princípios do desenho universal para a concepção ou adaptação de espaços, objetos e produtos que possam ser utilizados por usuários com capacidades diferentes (Center for Universal Design, 1997). Os dois programas também conseguem atender as 5 etapas do ciclo básico de acessibilidade das praias durante o seu período de funcionamento, representando um avanço rumo à equiparação de oportunidades, mas no caso do Programa Praia Para Todos no Rio de Janeiro, este ainda não pode ser considerado como uma solução definitiva, uma vez que, enquanto as pessoas sem deficiência podem acessar as praias durante todo o ano, as pessoas com deficiência conseguem acessar as praias somente durante o período de funcionamento do programa, ou seja, somente na estação de verão.

A análise comparativa dos programas de acessibilidade das praias aponta que embora o Rio de Janeiro tenha sido palco da Copa do Mundo em 2014 e dos Jogos Olímpicos e Paraolímpicos em 2016 recebendo recursos especiais e demandado a atenção dos gestores públicos para as políticas de acessibilidade, a infraestrutura da orla de Santos demonstrou ser superior a do Rio de Janeiro, com destaque para os banheiros acessíveis e calçadas acessíveis. A acessibilidade no caso do Rio de Janeiro apresenta evidencias de adaptação para cumprimento da Lei, enquanto que o caso da cidade de Santos traz evidências dos princípios do desenho universal e da acessibilidade aplicados pela Prefeitura Municipal já na fase de concepção dos projetos urbanísticos.

A pesquisa de campo revela diferenças significativas entre os programas de acessibilidade das 15 praias investigadas nos Estados do Rio de Janeiro, São Paulo e Santa Catarina. Os programas de acessibilidade das praias de Santa Catarina não foram discutidos neste artigo por não atenderem as 5 etapas do ciclo básico de acessibilidade das praias, mesmo que de forma temporária durante o funcionamento no verão, principalmente pela falta de banheiros acessíveis. Em Florianópolis, por exemplo, a Prefeitura Municipal assinou em Fevereiro de 2015 um Termo de Ajuste de Conduta (TAC) se comprometendo, perante o Ministério Público, a implantar banheiros e criar acesso para pessoas com deficiência em 15 praias da capital do Estado de Santa Catarina (Notícias do Dia, 2015). Contudo, das 4 praias investigadas nos meses de Janeiro e Fevereiro de 2017, a única praia de Florianópolis que oferecia banheiro acessível tinha um equipamento hospitalar instalado no vaso sanitário apontando o predomínio da concepção médica da deficiência e a falta de conhecimento sobre normas técnicas de acessibilidade pelo órgãos públicos locais.

Apesar da falta de banheiros acessíveis nas praias de Florianópolis, um grupo de surfistas em parceria com empresas locais e o Corpo de Bombeiros iniciaram em 2017 um projeto 
de inclusão social pelo surf adaptado, batizado de Surf Sem Fronteiras com aulas de surf na praia da Barra da Lagoa nos finais de semana do verão para as pessoas com deficiência. Outra iniciativa que merece destaque é o Projeto Social Onda Azul criado em 2016 por pais e amigos de crianças autistas com apoio de um grupo de surfistas. O Onda Azul oferece uma nova abordagem de tratamento, lazer e inclusão social para pessoas com autismo por meio da prática do surf adaptado durante os finais de semana do verão na Praia do Santinho. Os dois projetos têm contado com o apoio dos comerciantes locais que emprestam os banheiros para os participantes.

A Prefeitura Municipal de Santos se destacou entre os 15 casos estudados de praias acessíveis devido as suas iniciativas de acessibilidade. Por meio do Viva o Bairro, um programa que organiza visitas periódicas dos representantes da Prefeitura Municipal em todos os bairros da cidade para ouvirem as demandas dos moradores em audiências públicas, a Prefeitura de Santos tem atendido as reivindicações da comunidade executando de forma consistente projetos urbanísticos acessíveis e fundamentados nos princípios do desenho universal (Prefeitura Municipal de Santos, 2017c).

A análise comparativa dos 15 casos estudados na dissertação de mestrado indica que a diferença significativa existente entre os programas de acessibilidade das praias está relacionada principalmente com a gestão pública municipal e a mobilização da comunidade em prol da reivindicação dos seus direitos.

\section{Conclusões}

A CRPD (United Nations, 2006) da qual o Brasil é signatário desde 2009, a Lei da Acessibilidade (Lei 10.098, 2000), a Lei Brasileira de Inclusão da Pessoa com Deficiência (Lei 13.146, 2015) e a Norma Técnica NBR 9050 de Acessibilidade a Edificações, Mobiliário, Espaços e Equipamentos Urbanos (ABNT, 2015) aqui brevemente apresentadas, marcam o avanço na formação do arcabouço legal e normativo voltados para a acessibilidade e inclusão social das pessoas com deficiência. No entanto, o estudo empírico revela a lacuna existente entre as normas e Leis que determinam a adoção dos princípios do desenho universal e sua efetiva aplicação nas praias do litoral Brasileiro.

A investigação realizada por uma pesquisadora insider em 15 praias de três Estados Brasileiros, divulgadas pela mídia como praias acessíveis, revelam uma diferença significativa entre os poucos programas de praias accessíveis existentes no Brasil. Os resultados da pesquisa apontam a postura dos governantes perante a causa, a gestão pública municipal e a mobilização da comunidade em prol da reivindicação dos seus direitos como fatores determinantes dessa diferença de escopo e impacto dos programas de acessibilidade.

Este estudo também revela o papel crucial das pessoas com deficiência como agentes de transformação da sua própria realidade que é também a realidade de 46 milhões de pessoas no Brasil e 1 bilhão de pessoas no mundo. As iniciativas de Henrique Saraiva com o Programa AdaptSurf, de Ricardo Gonzalez com o Programa Praia Para Todos, do arquiteto Ron Mace criador dos Princípios do Desenho Universal e fundador do Center for Universal Design nos Estados Unidos revelam uma resposta proativa contra o capacitismo. Inconformados com as barreiras urbanísticas e atitudinais que geram marginalização e 
impedem o pleno exercício de seus direitos, essas pessoas mudaram de posição: de vítima para agente de mudança, causando impacto coletivo necessário para transformação social. A inclusão social das pessoas com deficiência requer uma grande mudança de paradigma, não só no pensamento, mas também nas ações direcionadas à tradução de aspiração à realização. Para tanto, passos fundamentais devem ser dados para mudar o quadro de marginalização dessas pessoas, como a alteração da visão social; acatamento à legislação vigente sobre os direitos das pessoas com deficiência e aplicação dos princípios do desenho universal; mais verbas para programas de acessibilidade; envolvimento pleno de pessoas com deficiência como principais partes interessadas e agentes de mudança em todas as etapas do processo de inclusão social.

Percebe-se que somente a existência da legislação não é suficiente quando se busca a inclusão social, que muitas barreiras ainda precisam ser transpostas e, principalmente, são necessárias mudanças de atitude de toda a sociedade para com as pessoas com deficiência. Para futuras pesquisas sugere-se a realização de estudos de casos cross-culturais entre países da América Latina, que estão amparados pelo recente Acordo de Colaboração Latino Americano entre esses países para pesquisa e conhecimentos científicos voltadas as pessoas com deficiência.

\section{Bibliografia}

ABNT - Associação Brasileira de Normas Técnicas (2011). NBR 9050. Acessibilidade a edificações, mobiliário, espaços e equipamentos urbanos. Recuperado de http://www.pessoa comdeficiencia.gov.br/app/sites/default/files/arquivos/\%5Bfield_generico_imagensfilefield-description\%5D_164.pdf

Acesse (2017). Praia Para Todos Comemora 10 Anos. Recuperado de http://www.portalacesse. com/2017/12/29/praia-para-todos-comemora-10-anos/

AdaptSurf (2017). Guia AdaptSurf de Acessibilidade das Praias. Recuperado de http://www. adaptsurf.xpg.com.br/projetos_guia.pdf

Adler, P. e Adler, P. (1994). “Observational techniques”, em Denzin, N. e Lincoln, Y. (Eds.). Handbook of qualitative research. Thousand Oaks: Sage, pp. 377-392.

Center for Universal Design (1997). The Principles of Universal Design 2.0. Recuperado de https://projects.ncsu.edu/ncsu/design/cud/about_ud/udprinciplestext.htm

Drucker, P. (1987). Social innovation - Management's new dimension. Long Range Planning, 20 (6), pp. 29-34.

Eisenhardt, K. (1989). Building Theories from Case Study Research. Academy of Management Review, 14 (4), 532-550.

Folha de São Paulo (2011). Empreendedor Social: Onda Inclusiva. Recuperado de http:// www1.folha.uol.com.br/empreendedorsocial/finalistas/2011-henrique-luana-e-luizadaptsurf.shtml

GIA Global Industry Analysts Inc. (2011). Surfing: Global Strategic Business Report. San Jose: GIA. 
Globo Esporte (2014). Em Santos, Escola Radical de Surf Lança Prancha Multifuncional. Recuperado de http://globoesporte.globo.com/sp/santos-e-regiao/noticia/2014/11/emsantos-escola-radical-de-surf-lanca-prancha-multifuncional.html

Guinness (2005). Guinness World Records 2005 The 50th Anniversary Edition. London: Guinness World Records Limited.

Hawken, P. (2007). Blessed Unrest: How the Largest Movement in the World Came Into Being, and Why No One Saw It Coming. New York: Viking Penguin.

IOC International Olympic Committee (2017). Welcome to the Wonderful World of Surfing. Recuperado de https://www.olympic.org/news/welcome-to-the-wonderful-world-ofsurfing

ISA International Surfing Association (2014). ISA Celebrates 50 years of Success. Recuperado de https://www.isasurf.org/international-surfing-association-celebrate-50-years-successisa-50th-anniversary-world-surfing-games-punta-rocas-peru/

ISA International Surfing Association (2017). The Stance ISA World Adaptive Surfing Championship. Recuperado de https://www.isasurf.org/events/isa-world-adaptivesurfing-championship/

Kania, J. \& Kramer, M. (2011). “Collective Impact”, em Stanford Social Innovation Review, Winter.

Kanuha, V. (2000). "Being" native versus "going native": Conducting social work research as an insider. Social Work, 45(5), 439-447.

Lei ${ }^{\circ} 10.098$, de 19 de Dezembro de 2000 (2000) Estabelece normas gerais e critérios básicos para a promoção da acessibilidade das pessoas com deficiência ou com mobilidade reduzida. Recuperado de http://www.planalto.gov.br/ccivil_03/Leis/L10098.htm

Lei $n^{\circ} 13.146$, de 04 de Julho de 2015 (2015). Institui a Lei Brasileira de Inclusão da Pessoa com Deficiência (Estatuto da Pessoa com Deficiência). Recuperado de http://www. planalto.gov.br/ccivil_03/_Ato2015-2018/2015/Lei/L13146.htm

Mace, R., Hardie, G. e Place, J. (1991). “Accessible environments toward Universal Design”, em Preiser, W.; Vischer, J. \& White, E. (Eds.) (1991). Design interventions: toward a more humane architecture. New York: Van Nostrand Reinhold.

Mintzberg, H. (2015). Time for the Plural Sector. Stanford Social Innovation Review, Summer.

Mobility Advisor (2017). Beach Wheelchair Information. Retrieved from https://www. mobility-advisor.com/beach-wheelchair.html

National Center of Accessibility (2017). Products Directory: portable beach access pathways. Recuperado de http://www.ncaonline.org/products-directory/product-list/mobi-mat.shtml

Nichols, W. (2014). Blue Mind: The Surprising Science That Shows How Being Near, In, On, or Under Water Can Make You Happier, Healthier, More Connected, and Better at What You Do. New York: Back Bay Books.

Notícias do Dia (2015). Praias de Florianópolis Terão Mais Acessibilidade. Recuperado de https://ndonline.com.br/florianopolis/noticias/acessibilidade-nas-praias-de-florianopolis

Pereira, A. M. B. A. (2008). Viagem ao Interior da Sombra: deficiência, doença crônica e invisibilidade numa sociedade capacitista (Dissertação de Mestrado em Sociologia), Universidade de Coimbra, Coimbra, Portugal.

Phills Jr., J.A.; Deiglmeier, K. \& Miller, D.T. (2008). Rediscovering Social Innovation. Stanford Social Innovation Review, 6, 34-46. 
Prefeitura Municipal de Santos (2017a). Turismo: Conheça Santos. Recuperado de http:// www.santos.sp.gov.br/portal/?q=content/conheca-santos

Prefeitura Municipal de Santos (2017b). Infraestrutura: Jardim da Orla de Santos. Recuperado de http://www.santos.sp.gov.br/portal/infraestrutura

Prefeitura Municipal de Santos (2017c) Viva O Bairro. Recuperado de http://www.santos. sp.gov.br/portal/viva-o-bairro

Reynolds, Z. \& Hritz, N. M. (2012). Surfing as adventure travel: Motivations and lifestyles, Journal of Tourism Insights, 3(1), pp. 1-17.

Sassaki, R. K. (2010). Inclusão: Construindo uma Sociedade para Todos (7a Edição). Rio de Janeiro: WVA.

SNPD - Secretaria Nacional de Promoção dos Direitos das Pessoas com Deficiência (2012) Convensão sobre Direitos das Pessoas com Deficiência e Protocolo Facultativo. Recuperado de http://www.pessoacomdeficiencia.gov.br/app/sites/default/files/publicacoes/convencao pessoascomdeficiencia.pdf

SNPD - Secretaria Nacional de Promoção dos Direitos das Pessoas com Deficiência (2017). Brasil assina termo de cooperação latino-americana pela inclusão. Recuperado de http:// www.pessoacomdeficiencia.gov.br/app/noticias/brasil-assina-na-onu-termos-decooperacao-latino-americana-pela-inclusao-com-chile-colombia

SEDPcD-SP - Secretaria de Estado dos Direitos da Pessoa com Deficiência de São Paulo (2015). Programa Praia Acessível: verão para todos no Estado de São Paulo. Recuperado em http://www.pessoacomdeficiencia.sp.gov.br/ultimas-noticias/programa-praiaacessivelverao-para-todos-no-estado-de-sao-paulo

Siqueira, D. (2017). Praias Acessíveis: uma análise jurídica e espacial para Florianópolis a partir da Convenção da ONU sobre os Direitos das Pessoas com Deficiência e das premissas do Desenho Universal (Dissertação de Mestrado em Arquitetura e Urbanismo). Universidade Federal de Santa Catarina, Florianópolis, SC, Brasil. Recuperado de http:// www.bu.ufsc.br/teses/PGAU0130-D.pdf

Taylor, J. (1970). Introducing Social Innovation. Journal of Applied Behavioral Science, 6 (1), pp. 69-77.

Thiollent, M. (1992). Metodologia da Pesquisa-Ação. São Paulo: Cortez.

United Nations (2006). Convention on the rights of persons with disabilities. Recuperado de https://www.un.org/development/desa/disabilities/convention-on-the-rights-ofpersons-with-disabilities.html\#Fulltext

United Nations (2016). The Invisibility of Disability: Why Disability Statistics Matters. Recuperado de http://www.un.org/disabilities/documents/sdgs/infographic_statistics_2016.pdf

United Nations (2017). Operationalizing the 2030 Agenda: Ways forward to improve monitoring and evaluation of disability inclusion. Recuperado de http://www.un.org/disabilities/ documents/desa/operationalizing_2030_agenda.pdf

Universo Online (2014). Programa Praia Acessivel: Cadeiras Anfíbias no Litoral Paulista promovem Accessibilidade o Ano Todo. Recuperado de http://www2.uol.com.br/guiadolitoral/materias/programa_praia_acessivel-3102-2014.shtml

WHO - World Health Organization (2011). World Report on Disability. Recuperado de http://www.who.int/disabilities/world_report/2011/accessible_en.pdf

Young, M. (1983). The Social Scientist as Innovator. Cambridge, Mass: Abt Books. 
Resumen: El ocio junto a la naturaleza es un derecho de todos, sin embargo, el acceso a las playas sigue siendo un gran desafío para las personas con discapacidad o movilidad reducida. El propósito de este artículo es estimular iniciativas dirigidas a la accesibilidad de las playas y la inclusión social de las personas con discapacidad a través de la aplicación de los principios del diseño universal en los proyectos urbanísticos y de la práctica de deportes adaptados. Este artículo hace una breve introducción sobre los derechos de las personas con discapacidad, los principios del diseño universal y el papel de la innovación social en la construcción de una sociedad inclusiva y discute los resultados de un estudio empírico pionero en Brasil realizado por una investigadora insider que evaluó su grado de accesibilidad de las playas accesibles brasileñas y los programas de inclusión social a través del surf adaptado, considerados casos de éxito de innovación social. Este artículo también apunta a despertar el interés de los investigadores en la realización de estudios cross-culturales de accesibilidad en los países de América Latina.

Palabras clave: Inovación Social - Diseño Universal - Accesibilidad - Movilidad reducida - Surf Adaptado.

Abstract: Leisure in nature is a right for everyone, however access to beaches is still a major challenge for people with disabilities or reduced mobility. The purpose of this article is to stimulate initiatives aimed at promoting accessibility of beaches and the social inclusion of people with disabilities through the incorporation of the universal design principles in urban projects and the practice of adapted sports. This article gives a brief introduction on the rights of people with disabilities, the principles of universal design and the role of social innovation in building an inclusive society. It also discusses the results of a pioneering empirical study in Brazil conducted by an insider researcher who tested the accessibility programs of Brazilian beaches and social inclusion programs through adapted surf, considered to be successful cases of social innovation. This article also aims to raise the interest of researchers in cross-cultural studies of accessibility in Latin American countries.

Keywords: Social innovation - Universal Design - Accessibility - Reduced mobility Adapted Surf. 